\title{
Treatment of stroke after carotid endarterectomy using intravenous abciximab
}

\author{
P. N. Sylaja ${ }^{1,2}$, Melissa Setiawan ${ }^{1}$, Michael D. Hill ${ }^{1}$, Andrew M. Demchuk ${ }^{1}$, John Wong ${ }^{1}$ \\ ${ }^{1}$ Calgary Stroke Program, Division of Neurosurgery and Department of Clinical, Neurosciences, University of Calgary, Alberta, \\ ${ }^{2}$ Department of Neurology, Ananthapuri Hospitals and Research Institute, Trivandrum, India
}

\author{
Address for correspondence: \\ Dr. P. N. Sylaja, \\ Department of Neurology \\ Ananthapuri Hospitals and Research \\ Institute, Thiruvananthapuram, \\ Kerala, India. E-mail: sylajapn@ \\ hotmail.com
}

DOI: $10.4103 / 0028-3886.59477$

\begin{abstract}
A 59-year old man developed perioperative stroke following left carotid endarterectomy seconday to thrombosis at the endarterectomy site. Transcranial Doppler ultrasonography revealed very frequent microembolization in the left middle cerebral artery territory. The patient was successfully treated with intravenous abciximab with complete neurological recovery.
\end{abstract}

Key words: Abciximab, carotid endarterectomy, stroke

\section{Introduction}

Carotid endarterectomy (CEA) is of proven value in the management of symptomatic carotid stenosis. However, the overall benefit of surgery is critically dependant on the perioperative stroke and mortality. Studies are now being focused on the strategies in reducing the risk of perioperative stroke, thus improving the safety of CEA. Intraoperative transcranial Doppler (TCD) monitoring and completion angioscopy have been found to reduce the risk of intraoperative strokes, but postoperative strokes due to thrombosis of the endarterectomy zone still complicate $2.7 \%$ of CEAs. ${ }^{[1]}$ There is evidence to suggest that detection of postoperative microembolic signals (MES's) after CEA can identify the patients at risk for cerebral ischemia., ${ }^{[2]}$ We report a patient successfully treated with intravenous (IV) abciximab for perioperative stroke secondary to thrombosis at the endarterectomy site with frequent MES's on TCD.

\section{Case Report}

A 59-year-old right-handed man with history of hypertension came to the emergency department with history of headache and sudden inability to write, dial telephone, and difficulty in using fork and knife for eating. On examination, he had ideational apraxia, agraphia, acalculia, and right-left disorientation suggestive of a left parietal lobe syndrome. The rest of the neurological examination was normal. A noncontrast computed tomography (CT) brain did not reveal any acute ischemic changes. Brain magnetic resonance imaging (MRI) done the next day showed multiple small restricted diffusion-weighted lesions in the left middle cerebral artery (MCA) territory [Figure 1]. Investigations for the cause of stroke revealed 65\% stenosis (North American Symptomatic Carotid Endarterectomy Trial (NASCET method) of the left internal carotid artery (ICA) and he underwent left CEA (without patch angioplasty) 13 days after the acute stroke. Eight hours after the CEA he developed acute onset of global aphasia with right hemiplegia with a National Institute of Health Stroke Scale (NIHSS) score of 16. Noncontrast CT brain showed a subacute left parietal infarct, but no hemorrhage or new ischemia. A CT angiography of the head and neck revealed a nonocclusive thrombus at the site of endarterectomy [Figure 1] and possible distal emboli in the left middle cerebral artery.

Various therapeutic options were considered. Urgent surgical re-exploration of the carotid artery and clot removal was discussed but would require vessel cross-clamping and thereby theoretically potentiate further cerebral ischemia and would not address the 


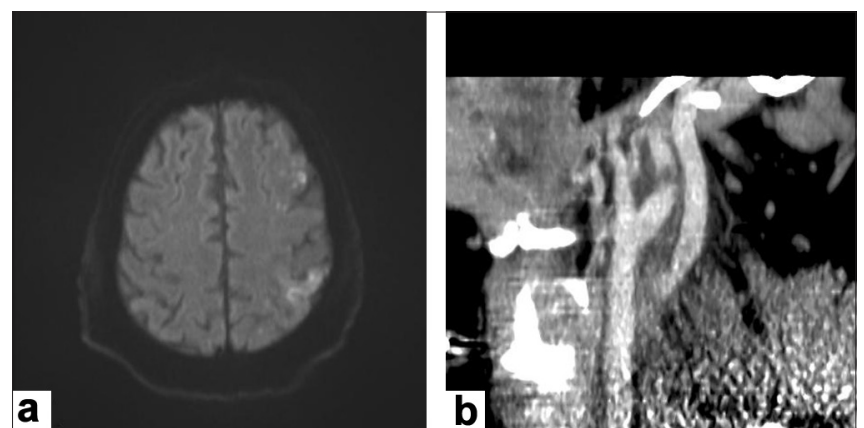

Figure 1: (a) Magnetic resonance imaging diffusion weighted image showing acute ischemic lesions in the left middle cerebral artery territory; (b) Computed tomography angiography (sagittal image) done after stroke following carotid endarterectomy with thrombus in the left internal carotid artery

intracranial emboli. Interventional catheter-based techniques for mechanical or chemical thrombolysis were thought to harbor risk of dislodging the carotid thrombus or disrupting the arteriotomy suture line. Use of tissue plasminogen activator (tPA), a potent agent for clot dissolution indicated for acute ischemic stroke, was not considered due to concerns of hemorrhagic conversion of the prior subacute cerebral infarct and possible bleeding at the surgical site.

Although no firm evidence demonstrates abciximab is superior to other thrombolytic agents in terms of bleeding risk, with the platelet-rich thrombus at the endarterectomy site, abciximab was considered as the best treatment to both dissolve the intravascular clot and prevent further platelet aggregation. An intravenous (IV) rather than intra-arterial route was considered because of speed of administration. To mitigate concerns of causing a neck hematoma and life-threatening airway obstruction after thrombolysis, and to address blood pressure control issues associated with stroke, the patient was urgently transferred to the intensive care unit and prophylactically intubated with close hemodynamic monitoring. The patient was then given a bolus of IV abciximab $(0.25 \mathrm{mg} / \mathrm{Kg})$, followed by a $0.125 \mathrm{mcg} / \mathrm{kg} / \mathrm{min}$ infusion over the next 12 hours. Immediately after the bolus of medication TCD ultrasonography revealed a dramatic reduction in microemboli from two MES's per minute prior to abciximab to zero afterwards [Figure 2]. The patient's motor deficits rapidly improved and by the next day were nearly completely resolved. No neck hematoma developed. Follow-up head CT scan showed no new hemorrhage. The patient was extubated without complication a day later and discharged home three days after surgery. On follow up one month later, his modified Rankin scale was 0.

\section{Discussion}

Evidence suggests that a majority of the perioperative strokes after CEA are intraoperative strokes which

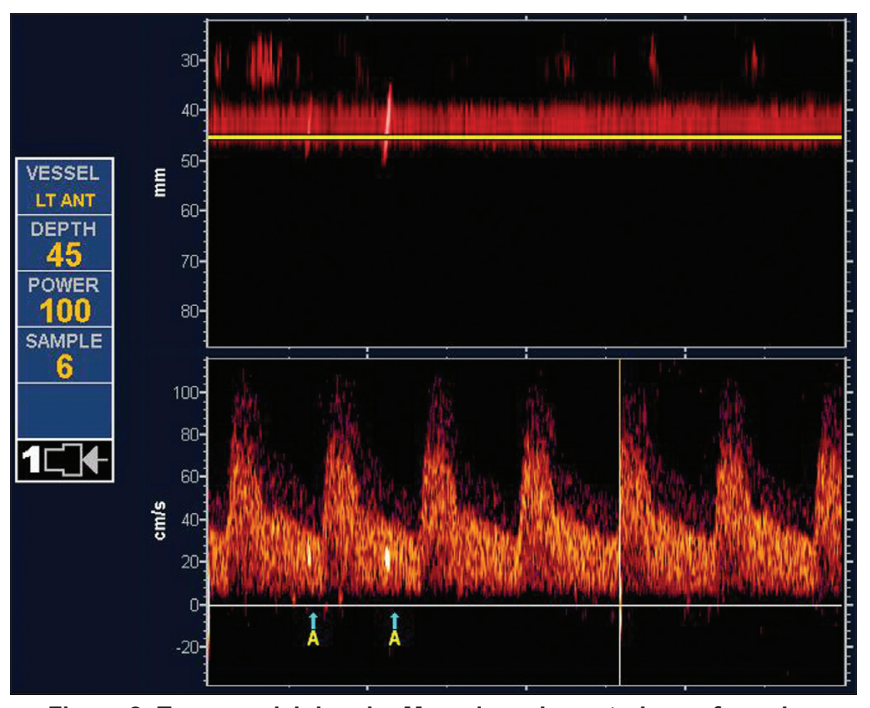

Figure 2: Transcranial doppler M-mode and spectral waveform done immediately after stroke showing two microemboli from the middle cerebral artery

are apparent immediately after anesthesia and is usually due to some adverse event during surgery ${ }^{[3]}$ Less common are the postoperative ischemic strokes which occur later and are usually due to thromboembolization. The presence of thrombus at the endarterectomy site and the high microembolic load detected by TCD after the stroke in our patient suggest that he was at high risk of cerebral ischemia. Increased thrombogenicity from a deeper endarterectomy plane, heightened platelet aggregability, and suboptimal operative angiographic result are the risk factors for thrombus formation at the operative site..$^{[2,4,5]}$ In retrospect, a recovery room TCD monitoring in the early postoperative course would have identified the high risk for cerebral ischemia in out patient. The dramatic clinical improvement seen in our patient with reduction in the MES's following treatment with abciximab was definite evidence for benefit of the drug in this clinical setting. Since embolization from the thrombotic fragment at the surgical site is the likely cause for the stroke, the recent evidence of successful use of abciximab in strokes and coronary stenting led us to use abciximab in this patient. ${ }^{[6-8]}$

Abciximab is effective in limiting thrombus propagation by reducing the interaction between platelets and monocytes. ${ }^{[7]}$ Combination of intra-arterial urokinase and IV abciximab has been found to produce a higher recanalization and better functional outcomes. ${ }^{[9]}$ Barkhoudian et al. for the first time used IV abciximab as a rescue therapy for stroke after CEA ${ }^{[10]}$ We demonstrated in our patient marked reduction of MES's on TCD after abciximab. However, in general the use of abciximab for the treatment of acute ischemic stroke is still limited. The results of the randomized phase 2 trial showed that abciximab could be given to patients with acute ischemic stroke with reasonable safety and showed favorable outcome at three months. ${ }^{[11]}$ But subsequent data from a larger randomized controlled phase 3 trial 
demonstrated increased bleeding risk associated with abciximab and the trial was aborted. ${ }^{[12]}$ Although the clinical scenario described in our report is exceptional, our experience suggests that with judicious and careful patient selection and appropriate monitoring, abciximab may be used successfully in postoperative stroke after CEA.

\section{References}

1. Lennard N, Smith JL, Gaunt ME, Abbott RJ, London NJ, Bell PR, et al. A policy of quality control assessment helps to reduce the risk of intraoperative stroke during carotid endarterectomy. Eur J Vase Endovase Surg 1999;17:234-40.

2. Levi CR, O'Malley HM, Fell G, Roberts AK, Hoare MC, Royle JP, et al. Transcranial Doppler detected cerebral microembolism following carotid endarterectomy. High microembolic signal loads predict postoperative cerebral ischemia. Brain 1997;120:621-9.

3. Krul JM, van Gijn J, Ackerstaff RG, Eikelboom BC, Theodorides T, Vermeulen FE. Site and pathogenesis of infarcts associated with carotid endarterectomy. Stroke 1989;20:324-8.

4. Gaunt ME, Martin PJ, Smith JL, Rimmer T, Cherryman G, Ratliff DA, et al. Clincal relevance of intraoperative embolization detected by transcranial Doppler ultrasonography during carotid endarterectomy: A prospective study of 100 patients. Br J Surg 1994;81:1435-9.

5. Gaunt ME, Ratliff DA, Martin PJ, Smith JL, Bell PR, Naylor AR. On-table diagnosis of incipient carotid artery thrombosis during carotid endarterectomy by transcranial Doppler scanning. J Vas Surg $1994 ; 20: 104-7$
6. Abciximab in Ischemic stroke investigators.Abciximab in acute ischemic stroke: A randomized, double-blind placebo-controlled dose escalation study. Stroke 2000;31:601-9.

7. Kopp CW, Steiner S, Nasel C, Seidenger D, Mlekusch I, Lang W, et al. Abciximab reduces monocyte tissue factor in carotid angioplasty and stenting. Stroke 2003;34:2560-7.

8. Qureshi AI, Suri MF, Ali Z, Kim SH, Lanzino G, Fessler RD, et al. Carotid angioplasty and stent placement: A prospective analysis of perioperative complications and impact of intravenously administered abciximab. Neurosurgery 2002;50:466-73.

9. Lee DH, Jo KD, Kim HG, Choi SJ, Jung SM, Ryu DS, et al. Local intra-arterial urokinase thrombolysis of acute ischemic stroke with or without intravenous abciximab: A pilot study. J Vase Inter Radiol 2002;13:769-74

10. Barkhoudarian G, Ali MJ, Deveikis J, Thompson BG. Intravenously administered abciximab in the management of early cerebral ischemia after carotid endarterectomy: Case report. Neurosurgery 2004;55:709.

11. Abciximab Emergent Stroke Treatment Trial (AbESTT) Investigators. Emergency administration of abciximab for treatment of patients with acute ischemic stroke; results of a randomized phase 2 trial. Stroke $2005 ; 36: 880-90$

12. Adams HP Jr, Effron MB, Torner J, Frayne J, Teal P, Leclerc J, et al. Emergency administration of abciximab for treatment of patients with acute ischemic stroke: Results of an international phase III trial: Abciximab in Emergency Treatment of Stroke Trial (AbEST'T-II) Stroke 2008;39:87-99.

Accepted on 31-03-2009

Source of Support: Nil, Conflict of Interest: None declared. 